\title{
Do bambu ao macaco: \\ Análise da violência contra as práticas culturais Guarani na contemporaneidade $^{1}$
}

\author{
Del bambú al mono: \\ Análisis de la violencia contra las prácticas culturales Guaraní en la \\ contemporaneidade \\ From bamboo to monkey: \\ Analysis of violence against contemporary Guarani cultural practices
}

Osmarina de Oliveira ${ }^{2}$

\begin{abstract}
Resumo
O presente artigo tem por objetivo, tratar sobre dois casos de violências contra os povos indígenas no tempo presente. O primeiro caso foi registrado em Santa Helena, oeste do Paraná e levado a cabo pela Polícia Ambiental. Os Guarani foram presos por dois dias na sede da Polícia Federal no município de Foz do Iguaçu e estão em cárcere domiciliar há mais de um ano, e foram indiciados pela Polícia Federal, pelo MPF e pelo juiz da $5^{\text {a }}$ Vara Federal de Foz do Iguaçu, pelo corte de um bambu para a utilização em um ritual religioso tradicional. O segundo caso foi registrado em Porto Alegre, Rio Grande do Sul, efetivado pela Guarda Municipal daquele município que apreendeu uma indígena com os seus dois filhos que vendiam artesanato no "Brique da Redenção" por ela estar com um macaquinho da espécie bugio, como bicho de estimação de seus filhos. Em ambos os casos os Guarani sofreram violência por agentes públicos, por praticarem atos de natureza tradicional. Buscaremos compreender a tipificação desses atos como criminosos pela justiça brasileira e de natureza tradicionais relacionado a práticas milenares pela população Guarani. Quando o direito de uns se sobrepõe ao dos outros e como práticas criminosas contra o meio ambiente são toleradas em nome do progresso e do desenvolvimento.
\end{abstract}

Palavras Chaves: Guarani; Território; Tradição; Violência.

\section{Resumen}

El presente artículo tiene por objetivo tratar sobre dos casos de violencias contra los pueblos indígenas en el tiempo presente. El primer caso fue registrado en Santa Helena, oeste de Paraná y llevado a cabo por la Policía Ambiental. Los guaraníes fueron arrestados y están en cárcel domiciliar por el corte de un bambú para su utilización en un ritual religioso tradicional. El segundo caso fue registrado en Porto Alegre, Rio Grande do Sul, efectuado por la Guardia Municipal de aquel municipio que aprehendió a una indígena con sus dos hijos que vendían artesanías en el "Brique de la Redención" por ella estar con un mono de la especie bugio, como bicho de los hijos. En ambos casos los Guaraníes sufrieron violencia por agentes públicos, por practicar actos de

\footnotetext{
${ }^{1}$ Artigo apresentado no Simpósio Temático ST - Diálogos interculturais de fronteiras perspectivas teóricas e experiências compartilhada durante o II Seminário Latino-Americano de Estudos em Cultura - SEMLACult em Foz do Iguaçu/PR, Brasil, 2018.

2 Graduada em Geografia pela UDESC; Mestranda do Programa Interdisciplinar em Estudos Latino-Americanos - IELA da Universidade Federal da Integração Latino-Americana e Membro do Conselho Indigenista Missionário - Cimi Regional Sul, Colaboradora do Projeto de extensão Vivências Interculturais: Ações da Unila no fortalecimento da cultura Guarani (PJ068-2019); Foz do Iguaçu, Paraná, Brasil; osmarina66@ gmail.com
} 
naturaleza tradicional. Buscaremos comprender la tipificación de esos actos como criminales por la justicia brasileña y de naturaleza tradicional relacionada a prácticas milenarias por la población guaraní. Cuando el derecho de unos se superpone al de los otros y como prácticas criminales contra el medio ambiente son toleradas en nombre del progreso y del desarrollo.

Palabras claves: Guaraní; Territorio; Tradición; Violencia.

\begin{abstract}
The purpose of this article is to deal with two cases of violence against indigenous peoples at the present time. The first case was registered in Santa Helena, western Paraná and carried out by the Environmental Police. The Guarani were imprisoned for two days at the Federal Police headquarters in the municipality of Foz do Iguaçu and have been in the home for more than a year and were indicted by the Federal Police, the MPF and the judge of the 5th federal branch of Foz do Iguaçu, by cutting a bamboo for use in a traditional religious ritual. The second case was registered in Porto Alegre, Rio Grande do Sul, made by the Municipal Guard of that municipality that seized an indigenous woman with her two children who sold handicrafts in the "Brique da Redenção" because she was with a little monkey of the howler monkey of their children. In both cases the Guarani suffered violence by public agents, for practicing acts of a traditional nature. We will try to understand the typification of these acts as criminals by the Brazilian courts and of a traditional nature related to millenarian practices by the Guarani population. When the law of some overlaps with that of others and as criminal practices against the environment are tolerated in the name of progress and development.
\end{abstract}

Key Words: Guarani; Territory; Tradition; Violence.

\title{
1. Introdução
}

O povo Guarani constitui um dos povos indígenas de maior presença territorial no continente americano. São mais de 280.000 pessoas, vivendo em 1416 comunidades indígenas na Argentina, na Bolívia, no Brasil e no Paraguai (MAPA CONTINENTAL GUARANI, 2016).

Atualmente, a maioria das comunidades Guarani vive em condições subumanas, em acampamentos debaixo de lonas, em pequenos pedaços de terras sem condições ambientais de produzir os seus sustentos e de tirar dali o seu material para os seus rituais religiosos. Pela sua concepção cosmológica fazem parte da natureza, e por isso procuram viver de maneira integrada com ela, mas devido a destruição da natureza por parte da sociedade regional, hoje, passaram a ser considerados intrusos em suas próprias terras, criminosos por querer seguir suas práticas tradicionais. Neste artigo vamos analisar dois casos de violências cometidas pelos órgãos públicos contra essa população, justamente por desejar dar continuidade as práticas tradicionais. O primeiro caso a ser analisado é sobre os Guarani que foram presos e estão em cárcere domiciliar há mais de um ano pelo corte de um bambu de Refúgio Biológico em Santa Helena (PR), para a utilização em um ritual religioso; o segundo caso a ser analisado foi registrado em Porto Alegre, Rio Grande do Sul, quando a Guarda Municipal apreendeu uma mulher Guarani com os seus dois filhos menores que vendiam artesanato no 
"Brique da Redenção" por ela estar com um macaquinho da espécie bugio, como bicho de estimação de seus filhos.

\section{A violência contra as práticas culturais}

\subsection{Tekoha Mokoi Joegua (Dois Irmãos)}

O Tekoha Mokoi Joegua localizado no município de Santa Helena, oeste do estado do Paraná foi retomado pelos Guarani em janeiro de 2017 depois de 35 anos, quando foram expulsos do local por conta formação do lago da hidrelétrica de Itaipu Binacional que inundou parte de seu antigo Tekoha ${ }^{3}$.

No dia 14 de março de 2018, 05 (cinco) Guarani moradores deste Tekoha, foram presos acusados de extrair um bambu e cortar três árvores de um refúgio biológico, unidade de conservação pertencente a Itaipu Binacional, mas que no passado recente fazia parte do seu antigo Tekoha.

Os cinco indígenas - Salutiano Avroca, Lourenço Bogado, Claudio Bararaka Mirim Bogado, Carlos Ferreira e Adenilson Acosta - fazem parte da referida comunidade e vivem numa península em frente ao Refúgio. Nesse dia foram até o local buscar um bambu para ser usados nos rituais religiosos da comunidade. Antes de saírem do refúgio e retornarem a aldeia, os Guarani cortaram um bambu ${ }^{4}$ e dividiram em três pedaços no tamanho do Takuapu (instrumento rítmico usado pelas mulheres em rituais religiosos), cerca de $1 \mathrm{~m} 30$ cada. Quando estavam retornando para a sua aldeia, foram surpreendidos, no meio do lago, pela Polícia Ambiental do Estado do Paraná que atende no município de Santa Helena, e levados diretamente para a sede da Polícia Ambiental, onde se iniciou uma série de violências: foram obrigados a sentar no chão, pois estavam "sujos" e não "deveriam” sentar nas cadeiras da delegacia para não sujá-las; o cacique Claudio, enquanto aguardava os policiais coletar os depoimentos, pegou em sua bolsa o Pentyngua (cachimbo usado também em cerimônias,

\footnotetext{
3 Tekoha se refere ao lugar da vivência do Teko (costumes, cultura e crenças).Segundo Melià (1987) sem Tekoha não há Teko, ou seja, sem um lugar apropriado não há cultura.

${ }^{4}$ No Brasil, as espécies mais conhecidas e disseminadas de bambu são aquelas de origem asiática. Algumas delas foram introduzidas pelos colonizadores portugueses (principais gêneros: Bambusa e Dendrocalamus), tendo sido trazidas de suas possessões na Ásia. (...) Além de fazer parte da típica paisagem rural brasileira, tais bambus começam a despertar o interesse econômico junto a diversas empresas. Retirado de http://apuama.org/historiabambu/ em
} 
portanto um instrumento sagrado) e o policial chefe chutou seu braço arremessando para longe o Petyngua, em seguida deu um soco em outro indígena ${ }^{5}$.

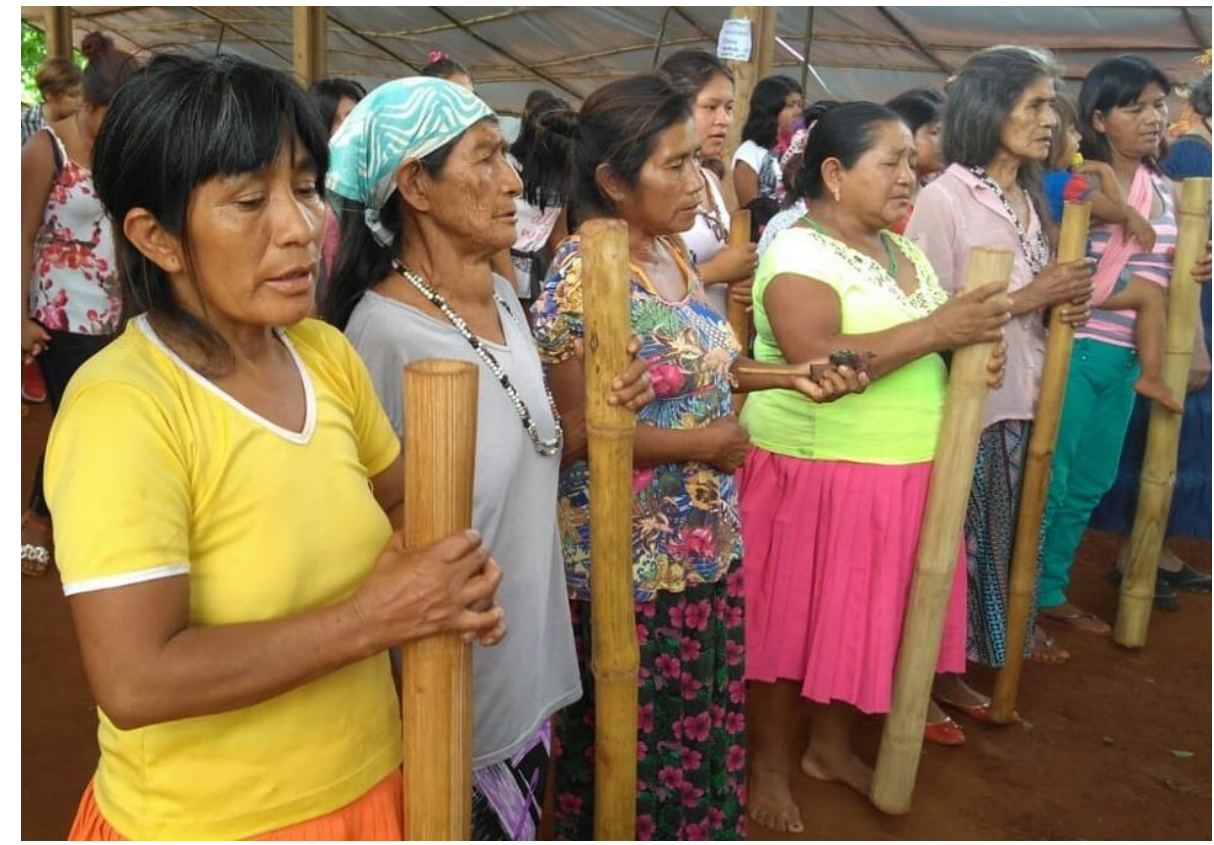

Figura 1 - Mulheres utizando o Takuapu durante o Encontro de Jovens Guarani (Aty Mirim) no Tekoha Itamarã, Município de Diamante do Oeste (PR).

Fonte: Cacique Celso Japoty Alves do Tekoha Ocoy.

A Polícia Ambiental depois de lavrar o auto de infração, realizou a transferência dos indígenas para a sede da Polícia Federal em Foz do Iguaçu. Logo em seguida, dois policiais estiveram na aldeia para comunicar os membros da comunidade a prisão dos cinco indígenas, e ali os policiais agrediram os membros da comunidade, o vice cacique Vilson Gonzales, relata que

dois policiais ambientais chegaram de barco na aldeia, e chegaram gritando, eles estavam armados e apontavam as armas em direção das crianças e das mulheres, inclusive tinha duas mulheres grávida, e começaram com ofensas, falou que nós não valia nada, que éramos paraguaio, que não tínhamos direito a nada aqui, disse que nós não éramos índio, que nós éramos animal e que nós não merecíamos nenhuma bala, e que se a gente cruzasse novamente para o outro lado vocês vão levar chumbo (...) o policial pediu pra identificar quem era a liderança, e quando eu falei que era o vice cacique, ele disse, agora você vai ser o próximo, você vai morrer também, e todo tempo ele disse assim você vai morrer, você vai morrer (...) isso deixou a comunidade muito assustada e com muito medo ${ }^{6}$.

Os cinco indígenas presos ao chegaram na sede da PF, foram interrogados pelo delegado de Plantão, que os indiciou pelo crime ambiental previsto no Art. 38 da Lei 9.605/98, relativo a "destruir ou danificar vegetação primária ou secundária, em estágio

\footnotetext{
${ }^{5}$ Relato do Cacique Claudio Vogado, sobre as violências sofrida na sede da polícia ambiental de Santa Helena. https://www.facebook.com/conselhoindigenistamissionario/videos/1565121286929531/?v=1565121286929531

${ }^{6}$ Relato feito durante o Encontro dos Oporaiva , que aconteceu no Tekoha Ocoy, município de São Miguel do Iguaçu, entre os dias 15 a 18 de março de 2018.
} 
avançado ou médio de regeneração". O delegado da Polícia Federal estabeleceu uma fiança de um mil reais para cada pessoa, totalizando um valor de cinco mil reais.

É importante destacar que o local da extração do bambu é caracterizado como de preservação ambiental, mas que sofreu um largo impacto quando da construção da hidrelétrica de Itaipu Binacional. É o local onde os Guarani em tempo não muito distante foram expulsos. É inegável que a área abrange o território de ocupação tradicional dos Guarani conforme o $\left(\operatorname{art.} 231, \S 1^{\circ}\right)^{7}$

Para fazer a defesa dos Guarani, foi necessário contar com o apoio do Centro de Direitos Humanos no Meio Popular (CDHMP), de Foz do Iguaçu, que fazem parte seus quadros, os dois advogados Hernan Aguillera e Ian Martin Vargas. Os advogados estiveram na sede da Polícia Federal e orientaram os Guarani a se manterem em silêncio durante o depoimento. Na assistência feita pelos advogados os Guarani relataram que haviam sido agredidos na sede da Polícia Ambiental, e por isso os advogados solicitaram uma audiência de custódia, que foi realizada no dia 15/03/2019 e posteriormente foram realizados o Exame de Lesões Corporais "Ad Cautela," n. 851/2018-MLC que comprovaram alguns edema e escoriações em duas pessoas do grupo.

Depois da decisão do delegado da Polícia Federal, os advogados demonstraram que a prisão era absurda e que a imputação da fiança no valor de cinco mil reais era um valor absurdo, já que os indígenas não tinham sequer calçados, e que até uma fiança de 10 reais já seria absurda. O juiz Edilberto Barbosa Clementino, então decidiu substituir o pagamento da garantia arbitrada pela Autoridade Policial pelas seguintes condições:

a) deverão comparecer perante este Juízo ou perante a Autoridade Policial sempre que necessário, sendo intimados por intermédio de seus advogados;

b) não poderão se ausentar da aldeia sem prévia solicitação de autorização a este Juízo (CLEMENTINO, 2018 p. 2)

Após dois dias na prisão na sede da Polícia Federal de Foz do Iguaçu, os Guarani foram soltos e passaram a cumprir a prisão domiciliar na aldeia.

A prisão dos cinco indígenas, desencadeou uma investida judicial da Itaipu Binacional, que detém a título do Refúgio Biológico de Santa Helena bem como da área ocupada pelos Guarani, e, no dia 15/03/2018 às 17h53m, entrou com uma ação de Manutenção e Reintegração de Posse de n. 5003164-49.2018.4.04.7002 e transformou os indígenas Salutiano Avroca, Lourenço Bogado, Cláudio Bararaka Mirim Bogado, Carlos

7 Parecer da Assessoria Jurídica do Conselho Indigenista Missionário. Disponível em; https://www.cimi.org.br/2018/03/os-indios-carta-politica-de-1988-e-prisao-por-uso-tradicional-da-taquara/ 
Ferreira e Adenilson Acosta como réus na ação. Às 20h27m57 do mesmo dia, a juíza Luciana da Veiga Oliveira, deferiu a tutela de urgência "para o fim de determinar a expedição de mandado de Manutenção da Posse em favor da Itaipu Binacional sobre a área do Refúgio Biológico de Santa Helena (área de 1.482 hectares), localizado no município de Santa Helena" (PROCESSO No 5003164-49.2018.4.04.7002 JF-Foz do Iguaçu). Com essa decisão os cinco indígenas se tornaram réus no processo movido pela Itaipu e por isso, tiveram que solicitar a assistência jurídica na Defensoria Pública da União (DPU), e hoje, eles e outros membros da comunidade indígena Mokoi Joegua estão impedidos de adentrar na área do Refúgio Biológico Santa Helena.

Além do Tekoha Mokoi Joegua, a Itaipu Binacional também entrou com ações de reintegração de posse contra os Tekoha Pyau, Curva Guarani e Ara Porã, Município de Santa Helena e contra o tekoha Yva Renda, município de Itaipulândia.

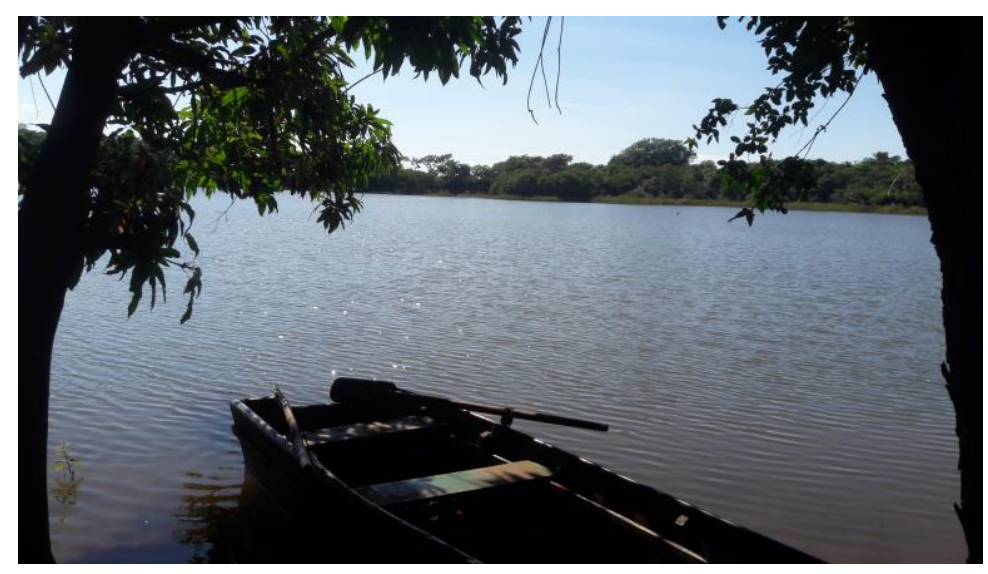

Figura 2 - Tekoha Mokoi Joegua, a visão da aldeia da área do Refúgio Biológico Santa Helena. O barco da foto é o mesmo que os indígenas foram presos quando saíram da área do refúgio. O barco foi retido no dia da prisão dos indígenas e levado para a sede da Polícia Ambiental, o barco não foi considerado como parte da investigação e o juiz mandou devolver o barco para os indígenas, mas até o momento isso não aconteceu.

Fonte: Clovis Antonio Brighenti

O Delegado da Polícia Federal, Emerson Antonio Rodrigues, enviou um memorando de ${ }^{\circ}$ 1427/2018-DPF/FIG/PR datado de 28/03/2018 para a Delegacia da Polícia Federal de Guaíra - Unidade-Técnico-Científica solicitando um Laudo Pericial sobre a área desmatada. a elaboração desse laudo. Esse oficio foi registado sobre o $\mathrm{n}^{\circ}$ 0503/18-NUTEC/FIG em 29/03/2018 e 0265/18-UTEC/GRA, em 06/04/18. Para este laudo foram elencados os seguintes quesitos: "Houve dano à flora dentro da área de preservação? Em caso positivo, descrever o dano e o instrumento utilizado. Qual a localização geográfica da área afetada? A área afetada é de preservação permanente? Outros dados reputado úteis pelo senhor perito”. 
Em 16 de maio de 2018, os peritos criminais André Rodrigues Lima e Eduardo de Oliveira Barros elaboraram o Laudo de no 332/2018 - UTEC/DFP/GRA/PR. No laudo os peritos contatam com o apoio do Sargento da Polícia Ambiental Adelar José Schimidt, para chegar até o local aonde teria sido retirado a vegetação. O laudo demonstra que:

foram encontrados os seguintes danos à vegetação, causados por instrumento manual de corte (facão, machadinha ou objeto de características equivalentes):

a) Uma árvore nativa jovem cortada no caule, com aproximadamente $7 \mathrm{~cm}$ (sete centímetros) de DAP (diâmetro a altura do peito - $1,30 \mathrm{~m}$ ) e $7 \mathrm{~m}$ (sete metros) de altura, localizada à aproximadamente $14 \mathrm{~m}$ (quatorze metros) das margens do Lago. O corte não foi completo, mas impossibilita a sobrevivência |

do vegetal, que se manteve em pé graças por estar apoiada nos vegetais do entorno (Figura 5);

b) Uma árvore nativa jovem cortada no caule, com aproximadamente $3 \mathrm{~cm}$ (três centímetros) de DAP e $3 \mathrm{~m}$ (três metros) de altura, localizada à aproximadamente 15 $\mathrm{m}$ (quinze metros) das margens do Lago (Figura 6) e;

c) Uma árvore nativa jovem cortada no caule, com aproximadamente $6 \mathrm{~cm}$ (seis centímetros) de DAP e $15 \mathrm{~m}$ (quinze metros) de altura, localizada à] aproximadamente $30 \mathrm{~m}$ (trinta metros) das margens do Lago (Figura 7).(LIMA e BARROS, 2018, p.5)

Após o envio da Perícia, o delegado da PF concluiu a investigação e encerrou o inquérito, e manteve a acusação de que os indígenas cometeram crime ambiental.

Após a conclusão do inquérito o delegado da PF encaminhado o processo para o Ministério Público Federal (MPF) em Foz do Iguaçu, no dia 14 de março de 2019, exatamente um ano da prisão dos Guarani. O Procurador da República de Foz do Iguaçu, Dr. Alexandre Collares, decidiu pelo indiciamento dos cinco indígenas. Sobre a alegação que os Guarani

praticaram de forma criminosa a conduta tipificada nos artigos 39, da Lei n. 9605/98, c/c art. 62, da lei n. 12651/12, c/c art. 29, do Código Penal pelo que se requer suas condenações, adotando-se para tanto o devido processo legal. Requer-se ainda a oitiva das testemunhas arroladas.

Contudo, em sendo atendidos os requisitos legais, sobretudo no tocante aos antecedentes criminais dos denunciados, proponho, nos moldes do artigo 89, da Lei n. ${ }^{\circ}$ 9.099/95 combinado com art. 28, da Lei n. 9605/98, a suspensão condicional do processo por dois anos, mediante as seguintes condições:

a) comparecimento bimestral em Juízo, para informar e justificar suas atividades;

b) proibição de ausentar-se do município de residência, sem autorização judicial;

c) prestação pecuniária para cada denunciado no valor equivalente a um salário mínimo na data dos fatos ou obrigação para cada denunciado de realizar a comprar e plantio de 5 mudas de espécies nativas em local a ser designado e sob a supervisão de funcionários/técnicos do Refúgio Biológico de Santa Helena/Itaipu Binacional (COLLARES, 2019 p. 4).

Atendendo a decisão da PF e do MPF, o Juiz Federal substituto da $5^{\text {a }}$ vara Federal, Daniel Chiaretti acolheu a denúncia de indiciamento dos indígenas

De outro turno, há aparente prova da materialidade e indícios de autoria, de modo que os fatos narrados apontam para uma conduta típica, ilícita e culpável, não havendo ocorrência de prescrição ou outra causa de extinção da punibilidade. Verifica-se, outrossim, a presença dos pressupostos processuais (competência do Juízo, aparente legitimidade da parte passiva e capacidade processual) e das condições para o exercício da ação penal (interesse de agir, legitimidade do 
Ministério Público Federal, já que se trata de ação penal pública incondicionada, e inexistência de condições objetivas de punibilidade e procedibilidade que devessem ser observadas). RECEBO a denúncia (CHIARETTI, 2019 p.1).

Contrariando a atitude do MPF em Foz do Iguaçu e acatando o pedido dos advogados de defesa, o juiz decidiu vincular a Funai na ação e decidiu por realizar uma Perícia antropológica. "Entendo ser o caso de produção de prova pericial antropológica a ser realizada nos acusados por profissional capacitado" (CHIARETTI, 2019 p.2). Na decisão, o juiz indica um antropólogo lotado na Coordenação Regional da Funai em Guarapuava para realizar a perícia.

Sobre a denúncia de que os indígenas teriam sido agredidos na sede da Polícia Ambiental, durante depoimento prestado na Audiência de Custódia realizada no dia 15/03/2018, o Procurador da República Dr. Alexandre Collares, desconsiderou o depoimento dos indígenas prestado na audiência e afirma que:

O Laudo do Exame de Lesões Corporais "Ad Cautelam" n. 851/2018-MLC, do exame da pessoa de Salustiano Avaroka constatou ofensa a integridade corporal, consistente em "escoriação em cotovelo direito", produzido por instrumento contundente. O Laudo do Exame de Lesões Corporais “Ad Cautelam" n. 854/2018MLC, do exame da pessoa de Cláudio Bararaka Mirim Bogado constatou ofensa a integridade corporal, consistente em "edema em $5^{\circ}$ quirodáctilo direito", produzido por instrumento contundente. Nos demais denunciados não houve constatação de ofensa a integridade corporal. (COLLARES, 2019b p.1)

(...)

Não se olvida que o exame pericial constatou lesões leves em dois dos denunciados - escoriação em cotovelo direito (Salustiano) e edema em $5^{\circ}$ quirodáctilo direito (Cláudio). Contudo, conforme consignado nos laudos periciais ambas foram produzidas por contusão, o laudo menciona "instrumento contundente", situação que, desacompanhada de outros elementos informativos, proporciona abertura para grande número de causas possíveis, desde simples caminhada em mata fechada com possibilidade de batida ou rapada em tronco de árvore (cotovelo), até acidente no manuseio de alguma ferramenta (dedos) (grifo nosso) (COLLARES, 2019b p.3).

No dia 30 de abril de 2019, o MPF-PR publicou uma matéria no seu site intitulada "Justiça acolhe denúncia de crime ambiental oferecida pelo MPF em Foz do Iguaçu"8 destacando o indiciamento dos Guarani e o arquivamento da denúncia de violência, cometida pela Polícia Ambiental contra os indígenas.

No caso ameaças da Polícia Ambiental de Santa Helena contra os membros da comunidade indígena, acabou não sendo objeto de investigação.

\footnotetext{
${ }^{8}$ Matéria disponível no site: http://www.mpf.mp.br/pr/sala-de-imprensa/noticias-pr/justica-acolhe-denuncia-decrime-ambiental-oferecida-pelo-mpf-em-foz-do-iguacu. Acesso em 13/05/2019.
} 


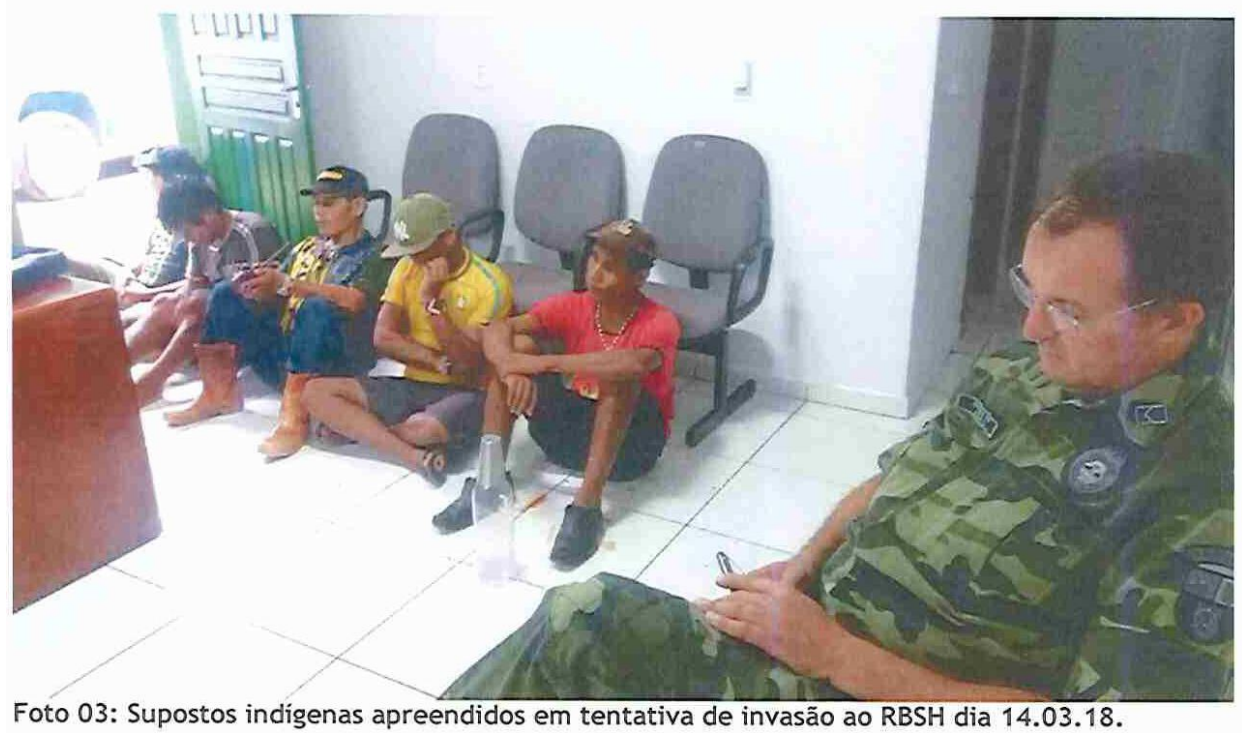

Figura 3 - Foto que consta no inquérito, onde demonstra os 5 Guarani sentados no chão na frente da cadeira, na sede da Polícia Ambiental de Santa Helena.

Fonte: Inquérito policial

\subsection{Parque Farroupilha em Porto Alegre}

O segundo caso que analisaremos aconteceu no dia 29 de abril de 2018 no Parque Farroupilha (conhecido como Parque da Redenção), em Porto Alegre/RS, quando a Guarani Teresa Gimenes, seus dois filhos menores de idade e um de seus animais de estimação (um macaquinho bugio) estava vendendo artesanato em um ponto da feira. Enquanto vendia o seu artesanato, Teresa foi constrangida por uma mulher, que passeava com seu animal de estimação (um cãozinho), que considerou absurda a presença de um animal silvestre, junto às crianças, e de imediato, procurou a Guarda Municipal de Porto Alegre e fez uma denúncia, alegando que Teresa estaria expondo à venda um "pequeno animal primata".

Os agentes da Guarda Municipal dirigiram-se ao local e deram voz de prisão à Teresa, conduzindo-a, juntamente com as crianças e o bichinho, até a Superintendência Regional da Polícia Federal. Depois de várias horas, foi elaborado um Termo Circunstanciado e encaminhado ao juiz Federal do Juizado Especial Criminal Federal de Porto Alegre. Na presença do Cacique Werá Jaime, da Terra Indígena do Cantagalo, município de Porto Alegre e do advogado Henrique de Oliveira, as $16 \mathrm{hs} 00$ do mesmo dia, Teresa foi liberada e pôde regressar para a sua comunidade, mas o animalzinho de estimação de seus filhos foi apreendido e levado a um abrigo para ser entregue ao Instituto Brasileiro do Meio Ambiente (IBAMA). É importante frisar que Teresa pouco fala o português e o entende muito 
precariamente, já suas crianças se comunicam exclusivamente em Guarani, e por isso não pôde compreender imediatamente os motivos de sua detenção e, no seu entender, suas crianças e o bugio também foram agredidos. $\mathrm{O}$ animalzinho que tinha uma convivência com as crianças foi engaiolado e afastado do convívio das mesmas.

Neste caso, o Ministério Público Federal em Porto Alegre, que ao contrário da ação de seu colega no oeste do Paraná, pediu o arquivamento do caso por considerar esse fato como não sendo um ato criminoso. Diante disso a PF arquivou o processo.

Os Guarani então solicitaram ao MPF que o macaquinho retornasse novamente ao convívio da comunidade Guarani. Diante dessa solicitação MPF abriu um Procedimento sob o $\mathrm{n}^{\mathrm{o}}$ 129.000.00.1548.2018-31, que posteriormente se tornou um Inquérito Civil Público de mesmo número, onde tem estudado formas de devolver o animal à comunidade Guarani ${ }^{9}$.

No momento da apreensão, macaquinho foi encaminhado para o Núcleo de Proteção Animal, onde se encontra em cativeiro. Caso ele seja devolvido aos Guarani, ele terá que passar por um processo de adaptação.
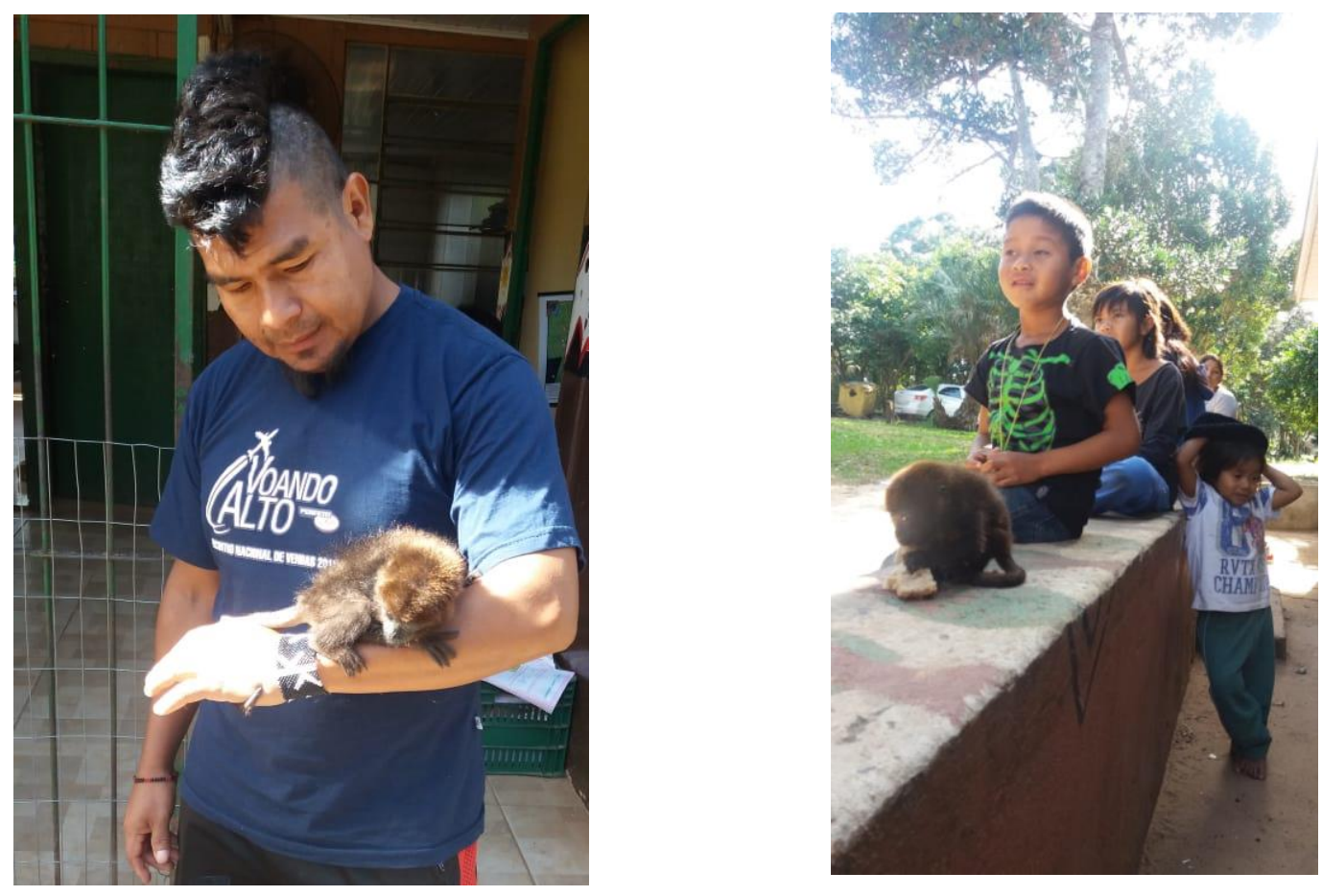

Figura 4 e 5 - Macaquinho como animais de estimação entre os Guarani no RS.

Fonte: Roberto Antônio Liebgott

\footnotetext{
${ }^{9}$ Informação repassada pelo telefone, por uma funcionária do MPF de Porto Alegre, que trabalha no Núcleo das Comunidades Indígenas e Minoria étnica.
} 


\section{Análise dos Casos}

Nos dois casos, ficou demonstrado o despreparo dos agentes e dos órgãos de segurança, mas fundamentalmente demonstra a existência de um profundo preconceito contra aqueles que têm uma identidade cultural diversa daquela considerada hegemônica.

A Assessoria Jurídica do Conselho Indigenista Missionário, observou em seu parecer que os indígenas que cortaram o bambu não cometeram crime ambiental e o ato de prisão, vale dizer, é ato de expressiva deselegância em face da Carta Política de 1988, pois a gravidade afeta quem mais a Constituição Federal de 1988 procurou preservar - os indígenas -, o que atesta a violação direta contra o Estado Democrático de Direito.

Essa é a mesma opinião do advogado e indigenista Fernando Mathias Baptista traz a baila que os povos indígenas não são obrigados a cumprir as normas de padrões ambientais, exigidas para a população não indígena, porque a $\mathrm{CF}$ reconhece aos indígenas os seus usos e costumes: que destaca que:

Na medida em que a exploração (de recursos naturais) se dê de acordo com os usos e costumes dos povos indígenas, não estão eles obrigados a cumprir com as normas e padrões ambientais exigidos para a população não indígena, pois a Constituição respalda seus usos e costumes como legítimos e reconhecidos pelo Estado brasileiro. Caso passem a explorar seus recursos naturais de forma diversa do que dita suas tradições e costumes de manejo, então passariam a estar sob o crivo da legislação ambiental, devendo observar as restrições ambientais para cada atividade pretendida (BAPTISTA, 2002, p.186).

A Promotora de Justiça do Ministério Público do Distrito Federal Juliana Santilli demonstra que se uma UC incide sobre terra indígena e os indígenas ao praticarem as suas atividades tradicionais, não estaria cometendo um crime.:

a caracterização do crime previsto no art. 40 da Lei de Crimes Ambientais: aquele que causar dano direto ou indireto às Unidades de Conservação ou ao seu entorno está sujeito a pena de reclusão de um a cinco anos. Se há uma superposição dos limites de Unidades de Conservação sobre terras tradicionalmente ocupadas por índios, não há como alegar que os índios, ao praticarem atividades tradicionais incompatíveis com a natureza da Unidade de Conservação - por exemplo, caçar ou pescar, ou coletar plantas ou sementes dentro de um Parque Nacional ou Reserva Biológica cujos limites incidem sobre Terras Indígenas - estejam praticando o referido crime (de dano a Unidade de Conservação). Se a Constituição assegura aos índios direitos originários sobre suas terras tradicionais, não há como responsabilizálos quando praticam atividades tradicionais, segundo seus usos, costumes e tradições, dentro de Unidades de Conservação cujos limites incidem sobre suas terras tradicionais - mesmo quando se trate de uma Unidade de Conservação de Proteção Integral, em que aquela atividade é vetada pela legislação ambiental. Se a categoria de Unidade de Conservação criada sobre os limites das Terras Indígenas é incompatível com as atividades tradicionais desenvolvidas pelos povos indígenas, não há como sustentar a sua validade jurídica em face dos direitos originários assegurados constitucionalmente aos povos indígenas (grifo nosso). (SANTILLI, 2004). 
Segundo a Procuradora da República, Caroline Marinho Boaventura Santos, as populações indígenas tem outra forma de conceber os recursos naturais, e que os órgãos ambientais deveriam garantir aos indígenas livre acesso sem impor exigências:

(...) os recursos naturais que lhes sustentam como parte indissociável tanto da existência individual quanto coletiva. Não há cisão ou separação estanque entre a existência humana e àquela presente na natureza, de modo a se conceber qualquer hierarquia entre o homem e o meio, no sentido de serem os recursos ambientais plenamente servis ao gozo da espécie humana. (...) Sendo assim, cabe à União, ao Estados e aos Municípios, e aos órgãos e entidades da Administração Indireta, garantir aos indígenas livre acesso aos meios indispensáveis à existência de suas comunidades, sem impor exigências, nem estabelecendo restrições que não se coadunam com a sua organização social peculiar e com suas tradições e costumes diferenciados (BOAVENTURA SANTOS, 2014).

Apesar desses argumentos apresentados acima, percebe-se que e mesmo dentro do Ministério Público Federal, não é um consenso, porque os argumentos apresentados pelo MPF de Porto Alegre referente ao caso da Guarani Teresa Gimenses, não foi observado pelo MPF de Foz do Iguaçu, que conclui pelo indiciamento dos cinco Guarani, pelo corte do bambu e outra vegetação.

O próprio Ministério Público Federal poderia ter convocado os cinco Guarani para prestar um novo depoimento, já que na sede da PF eles ficaram em silencio por recomendação dos seus advogados, mas isso não foi feito, precisando o juiz federal solicitar essa perícia.

É importante destacar que o laudo dos peritos e no próprio laudo da Polícia Ambiental, fala sobre a destruição da vegetação nativa, mas não identifica que tipo de árvore foram derrubadas.

Com base nestes fatos, que os órgãos públicos necessitam conhecer e respeitar as legislações e os direitos dos povos indígenas, para que não venham cometer novamente as violências que os Guarani vivenciaram na pele.

É importante observar também que esses casos se configuram como violência institucional, porque ela parte da lógica do Estado e de parte da sociedade, e da elite capitalista. Na ação discursiva do Estado é importante observar o que se tolera como práticas agressivas ao meio ambiente e o que não se tolera. No geral, práticas indígenas não são toleradas, mas práticas que tenham como abordagem discursiva o "progresso" e o "desenvolvimento" são totalmente toleradas, mesmo que incidam profundamente em prejuízos ambientais. O agronegócio é um exemplo, que utiliza além das sementes transgênicas e quantidade abusiva de veneno. 


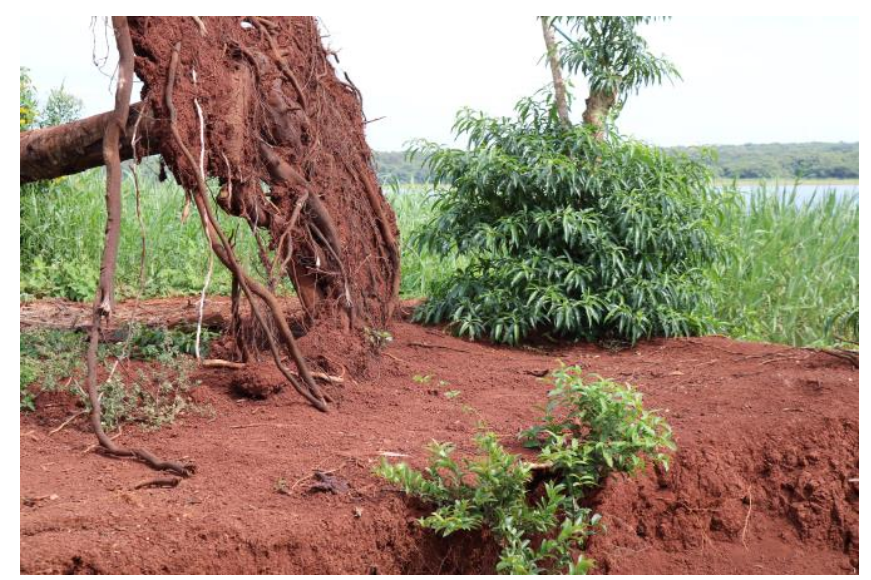

Figura 6 - Foto do Tekoha Mokoi Joegua que demostra uma árvore caída com as raízes exposta devido a ação da água que provoca erosão no lago da hidrelétrica de Itaipu.

Fonte: Osmarina de Oliveira, abril de 2019.

Os Guarani em uma "Manifestação do Encontro de Oporaiva" datada de 18 de março de 2018, afirmam, "não vamos admitir violências e agressores como ocorreram no passado. Queremos que as autoridades competentes investiguem e punam os agressores" (MANIFESTAÇÃO DO ENCONTRO DE OPORAIVA, 2018, p.3).

\section{Considerações Finais}

O caso dos cinco Guarani presos por cortarem um bambu da Reserva Biológica de Santa Helena para ser utilizado como instrumento religioso e, o caso da indígena Teresa Benites que foi presa por ter levado consigo como mascote um filhote de macaco bugio quando foi vender o artesanato no Parque Farroupilha em Porto Alegre/RS, demonstram o despreparo dos agentes públicos dos órgãos de segurança, em reconhecer os direitos dos povos indígenas e, um profundo preconceito contra aqueles que têm uma identidade cultural diversa daquela considerada hegemônica.

Chama-nos a atenção a violência empregada contra os Guarani. O que nossa legislação considera crime ambiental e como os gestores atuam com mais ou menos rigor a depender dos praticantes do "crime". Numa região notadamente marcada pela presença do agronegócio, em que o despejo de milhares de litros de venenos são lançados cotidianamente na terra, na água e nos alimentos é tolerado e aceito como natural, imputa-se prisão as comunidades tradicionais pelo corte de uma planta exótica para um ritual ou pela adoção de um animal silvestre que foram adotados por crianças indígenas conforme a sua cultura. Não se pode esquecer que quando ainda abundava a mata atlântica na região os Guarani ocupavam a terra 
de maneira integrada com a natureza, hoje, passaram a ser considerados intrusos em suas próprias terras, criminosos por querer seguir suas práticas tradicionais.

Porém, os Guarani e os povos indígenas seguem sua trajetória histórica de manutenção de sua cultura dentro dos limites possível, mas afirmando permanentemente que desejam viver a seu modo.

\section{Referências}

BAPTISTA, Fernando Mathias. LIMA, A. (org.). O direito para o Brasil socioambiental. São Paulo, Instituto Socioambiental; Porto Alegre, 2002.

BOAVENTURA SANTOS, Caroline Marinho. O uso dos recursos naturais pelos índios e a observância à legislação ambiental. Conteúdo Jurídico, Brasília-DF: 16 dez. 2014. Disponível em: http://www.conteudojuridico.com.br/artigo,o-uso-dos-recursos-naturais-pelos-indiose-a-observancia-a-legislacao-ambiental,51439.html.Acesso em: 13 maio 2018.

CHIARETTI, Daniel. Crimes Ambientais n. 5002938-10.2019.4.047002/PR. Foz do Iguaçu, 2019. Disponível em: http://www.mpf.mp.br/pr/sala-de-imprensa/noticias-pr/justica-acolhedenuncia-de-crime-ambiental-oferecida-pelo-mpf-em-foz-do-iguacu. Acesso em: 13 maio 2019.

CIMI - Grupo Guarani é preso no Paraná por retirar taquara de ilha da UHE Itaipu. Brasília: DF: Mar 2018. Disponível em:https://www.cimi.org.br/2018/03/grupo-guarani-epreso-no-parana-por-retirar-taquara-de-ilha-da-uhe-itaipu/ Acesso em: 14 de maio de 2018.

CIMI - Os índios, a Carta Política de 1988 e a prisão por uso tradicional da taquara, Brasília. DF: Mar 2018. Disponível em https://www.cimi.org.br/2018/03/os-indios-carta-politicade-1988-e-prisao-por-uso-tradicional-da-taquara/\#_ftn2 \&gt; Acesso em:14 de maio de 2018.

CIMI. A detenção de Teresa Gimenes Guarani Mbya pela Guarda Municipal de POA e o direito à diferença. Disponível em: https://www.cimi.org.br/2018/05/a-detencao-de-teresagimenes-guarani-mbya-pela- guarda-municipal-de-poa-e-o-direito-a-diferenca. Acesso em: 14 de maio de 2018.

CIMI. Justiça Federal acolhe denúncia e pede perícia para caso de grupo Avá-Guarani preso por três taquaras. Disponível em: https://cimi.org.br/2019/04/justica-federal-acolhedenuncia-e-pede-pericia-para-caso-de-grupo-ava-guarani-preso-por-tres-taquaras/. Acesso em: 05 de Abril de 2019.

CLEMENTINO, Eldiberto Barbosa. Inquérito Policial $N^{o}$ 5003102-09.2018.4.04.7002/PR Foz do Iguaçu, 2018.

COLLARES, Alexandre. IPL n. 0225/2018-DPF/FIG/PR (autos $n$. 500310209.2018.4.04.7002). Foz do Iguaçu 2019. Disponível em: http://www.mpf.mp.br/pr/sala-deimprensa/noticias-pr/justica-acolhe-denuncia-de-crime-ambiental-oferecida-pelo-mpf-em-fozdo-iguacu. Acesso em: 13 maio 2019

COLLARES, Alexandre. Autos IPL n. 0225/2018-DPF/FIG/PR (autos n. 5003102- 
09.2018.4.04.7002). Foz do Iguaçu 2019b.

JUSTIÇA FEDERAL. Inquérito Policial No 5003102-09.2018.4.04.7002/PR. Foz do Iguaçu, 2018.

JUSTIÇA FEDERAL. Reintegração/Manutenção de Posse $N^{o}$ 5003164-49.2018.4.04.7002, Foz do Iguaçu, 2018.

LIMA, André R, e BARROS, Eduardo de O. Laudo n. 332/2018. Laudo de Perícia Criminal Federal (Meio Ambiente). 2018, p.5). Disponível em: http://www.mpf.mp.br/pr/sala-deimprensa/noticias-pr/justica-acolhe-denuncia-de-crime-ambiental-oferecida-pelo-mpf-em-foz-doiguacu. Acesso em: 13 maio 2019

MANIFESTAÇÃO DO ENCONTRO DE OPORAIVA. Tekoha Ocoy, São Miguel do IguaçuPR, em 18 março. 2018.

MAPA GUARANI CONTINENTAL. Guarani Continental. Teta Guarani Argentina pegua Bolivia pegua Brasil pegua. Campo Grande: 2016.PEGUA

MELIÁ, B. La tierra sin mal de los guaraní economía y profecía. Suplemento antropológico, p. 81-97, 1987.

MOREIRA, Júlio da S. Uso ritual das Tacuaras pelos Guarani e sua violação no oeste do Paraná. Espirales Revista para a integração da América Latina e o caribe. v. 1, n. 2 marco/agosto 2018. Disponível em: https://revistas.unila.edu.br/espirales/article/view/1325 Acesso em: 02 abril de 2019.

PORÉM.NET. Indígenas Guarani são presos por cortarem um bambu de antiga aldeia no Paraná. Disponível em: http://porem.net/2018/03/15/indigenas-guarani-sao-presos-porcortarem-um-bambu-de-antiga-aldeia-no-parana/. Acesso em: 13 de maio de 2018.

PORÉM.NET. MPF denuncia indígenas por corte de três pedaços de bambu. Disponível em: https://porem.net/2019/03/28/mpf-denuncia-indigenas-por-corte-de-tres-pedacos-de-bambu/. Acesso em: 05 de Abril de 2019.

SANTILLI, Juliana. A lei de crimes ambientais se aplica aos índios? Disponível em: http://pib.socioambiental.org/pt/c/terras-indigenas/sobreposicoes/a-lei-de-crimes-ambientaisse-aplica-aos-indios. Acesso em: 13 de maio de 2018. 